\title{
Minimally invasive spinal surgery: a historical perspective
}

\author{
Issada Thongtrangan, M.D., Hoang Le, M.D., Jon Park, M.D., \\ AND DANIEL H. KIM, M.D. \\ Department of Neurosurgery, Stanford University Medical Center, Stanford, California
}

\begin{abstract}
The concept of minimally invasive spinal surgery embodies the goal of achieving clinical outcomes comparable to those of conventional open surgery, while minimizing the risk of iatrogenic injury that may be incurred during the exposure process. The development of microscopy, laser technology, endoscopy, and video and image guidance systems provided the foundation on which minimally invasive spinal surgery is based. Minimally invasive treatments have been undertaken in all areas of the spinal axis since the 20th century. Lumbar disc disease has been treated using chemonucleolysis, percutaneous discectomy, laser discectomy, intradiscal thermoablation, and minimally invasive microdiscectomy techniques. The initial use of thoracoscopy for thoracic discs and tumor biopsies has expanded to include deformity correction, sympathectomy, vertebrectomy with reconstruction and instrumentation, and resection of paraspinal neurogenic tumors. Laparoscopic techniques, such as those used for appendectomy or cholecystectomy by general surgeons, have evolved into procedures performed by spinal surgeons for anterior lumbar discectomy and fusion. Image-guided systems have been adapted to facilitate pedicle screw placement with increased accuracy. Over the past decade, minimally invasive treatment of cervical spinal disorders has become feasible by applying technologies similar to those developed for the thoracic and lumbar spine. Endoscope-assisted transoral surgery, cervical laminectomy, discectomy, and foraminotomy all represent the continual evolution of minimally invasive spinal surgery. Further improvement in optics and imaging resources, development of biological agents, and introduction of instrumentation systems designed for minimally invasive procedures will inevitably lead to further applications in minimally invasive spine surgery.
\end{abstract}

\section{KEY WORDS - history of surgery - minimally invasive spine surgery - endoscope • laparoscope - thoracoscope}

Since the 1930s, the relationship between disc herniation and sciatica has been well recognized. Since that time, intraoperative tools have been developed to facilitate surgical approaches and treatment of disc disease. Pool used a modified illuminated otoscope to perform myeloscopic examinations of the dorsal nerve roots in cases of disc herniations. ${ }^{71}$ In 1955 , Malis used the operating microscope and bipolar coagulation in facilitating his surgical approach. ${ }^{42}$ With the introduction of the operating microscope, Yaşargil and Caspar ${ }^{6}$ both described the minimally invasive concept of microdiscectomy. During the same period, biochemical advances in the treatment of disc herniations were also developed. In 1964, Smith ${ }^{74}$ was able to dissolve the nucleus pulposus in a rabbit model via percutaneous enzymatic applications; this technique was later successfully applied in humans. ${ }^{21}$ In 1975, Hijikata ${ }^{28}$ described the first percutaneous discectomy, which later evolved into automated discectomies. In addition to automated techniques, adjuvant treatments of discogenic disruption have included the use of lasers and thermal heat-

Abbreviations used in this paper: $\mathrm{BMP}=$ bone morphogenetic protein; $\mathrm{CT}=$ computerized tomography; IDET = intradiscal electrothermal therapy; KTP = potassium-tytinal-phosphate; LIF = lumbar interbody fusion; MED = microendoscopic discectomy; PLD = percutaneous lumbar discectomy; PMMA = polymethyl methacrylate; YAG = yttrium- aluminum-garnet. ing probes..$^{36,58,79}$ In 1984, Ascher and Heppner ${ }^{2}$ used an $\mathrm{Nd}$-YAG laser to heat the nucleus pulposus in attempts to shrink the disc and relieve the symptoms of nerve compression. Since the 1990s, with the application of video imaging to standard endoscopy, minimally invasive endoscopic and thoracoscopic procedures have gained rapid use and have diversified in their clinical applications. In this report, we review the historical perspectives and the concept of minimally invasive spinal techniques as they are used in different portions of the spinal column.

\section{LUMBAR SPINE}

\section{Chemonucleolysis}

Chymopapain was discovered and isolated by Jansen and Balls ${ }^{30}$ in 1941 from the latex of the fruit of Carica papaya. By depolymerizing the proteoglycan and glycoprotein macromolecules of the nucleus pulposus, chymopapain can reduce the water content of the extracellular matrix of the nucleus pulposus and cause reductions in intervertebral disc height and bulge. In addition to reducing intradisc pressure, chymopapain may also have an antiinflammatory role in the nerve root itself. Watts ${ }^{82}$ proposed that chymopapain interacts with the sensory fibers of the anulus to produce a total or partial neurectomy effect. 
The first clinical treatment of sciatica by using chymopapain was applied by Smith ${ }^{74}$ in 1964. In the following three decades, chemonucleolysis was actively used to treat disc disease; however, controversial issues surrounding its safety and efficacy, arose despite the fact that it has the approval of the US Food and Drug Administration. Overall, the efficacy of chemonucleolysis was noted to be between 74 and $77 \%$ in several reports. ${ }^{11,19,31}$ The largest series was reported by Nordby and Javid; ${ }^{54}$ they published a 14-year study of 3000 patients and noted a success rate ranging between 82 and $87.2 \%$. Other published outcome reports were inconclusive, however, and brought into question the safety and efficacy of chymopapain. . $^{31,53,55}$ Anaphylactic reactions to this substance can result in death. An inadvertent intrathecal chymopapain injection can cause hemiparesis and paraplegia, raised intracranial pressure, meningitis, and hemorrhage.

A review of the literature nevertheless does reveal data supporting the continued use of chemonucleolysis for the treatment of lumbar disc herniations. ${ }^{25,43,44,78,83}$ Proper patient selection is crucial for success. Chemonucleolysis should be reserved for patients with radicular symptoms caused by a soft herniated disc as demonstrated by imaging studies. Patients older than 60 years of age may lack sufficient mucoprotein for hydrolysis and tend to respond poorly to this procedure..$^{40}$ Absolute contraindications to chemonucleolysis include allergic reactions to papain, history of discitis, cauda equina syndrome, pregnancy, arachnoiditis, migrated discs, and canal stenosis.

\section{Percutaneous Lumbar Discectomy}

In 1975, Hijikata ${ }^{28}$ first described a percutaneous nucleotomy technique involving a partial resection of the disc material via a posterolateral approach. The procedure was performed using local anesthesia. In 1983, Kambin and Gellman ${ }^{35}$ performed a dorsolateral discectomy by inserting a Craig cannula and a small forceps into the disc space. In 1985, Onik and colleagues ${ }^{58}$ introduced a nucleotome for PLD. In 1986, Kambin and Sampson ${ }^{36}$ initiated the use of fluoroscopy for percutaneous discectomy. Instruments similar to those developed for ophthalmologists to remove the vitreous humor of the eye were redesigned for use in percutaneous discectomies; some flexibility was provided to approach the L5-S1 and L4-5 levels. ${ }^{57}$

Patient selection for percutaneous discectomy is similar to that used in patients undergoing chymopapain treatment. Similarly, the procedure of percutaneous discectomy is most ideal for contained disc fragments, with the size of the protrusion being an important factor in obtaining successful outcomes. ${ }^{20}$ In addition, patients with narrowed disc spaces are also poor candidates for percutaneous discectomy. Automated PLD can be a treatment option for patients with single-level disc disease (Fig. 1). It is not indicated for patients with a history of previous chemonucleolysis, surgical discectomy, progressive neurological deficits, sequestered disc fragments, spinal stenosis, or spondylolisthesis. Success rates reported in the literature range from 77.5 to $87 \%$ and the complication rate is $1 \% .^{12,13,45,59}$ To date, however, there have been no prospective randomized controlled studies to validate the long-term outcomes of PLD.

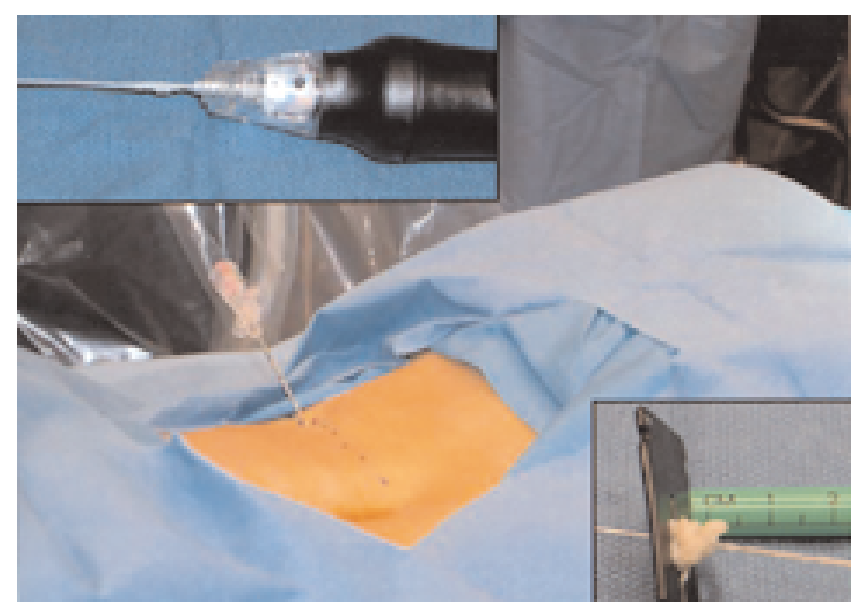

Fig. 1. Photographs related to an automated percutaneous discectomy. The needle (upper inset) placed through the triangular space and a large disc specimen (upper inset) is removed.

\section{Percutaneous Laser-Assisted Discectomy}

The development of laser light amplification by stimulated emission of radiation dates back to 1958 and was accomplished by Arthur L. Schawlow and Charles H. Townes. ${ }^{71}$ Since then, numerous applications of laser technology in medicine have been reported in the specialties of ophthalmology, plastic surgery, urology, vascular surgery, general surgery, gynecology, neurosurgery, and orthopedics. Laser-assisted discectomy evolved from percutaneous discectomy techniques. After percutaneous placement of a single needle in the disc space, laser energy is passed through a fiber, which is coupled to the needle, into the disc space. The laser energy is transmitted in short bursts to avoid excessive heating of adjacent tissue. In 1984, Ascher and Heppner ${ }^{2}$ used carbon dioxide and Nd lasers to treat lumbar disc disease. Their method involved measuring intradisc pressure before and after laser discectomy by using a saline manometer. These authors postulated that the removal of even a small volume of tissue from the disc caused a corresponding decrease in intradisc pressure, thus relieving back pain and inflammation. In 1990, Yonezawa, et al. ${ }^{88}$ used an Nd-YAG laser to transmit energy through a double-lumen needle with a bare quartz fiber; their tip-type pressure transducer was similarly able to record intradisc pressure. The use of a KTP laser for lumbar disc ablation was introduced in $1992 .{ }^{39}$ Recent advances have allowed the development of side-firing probes, which provide better directional control and visualization. The side-firing laser probe reduces the risk of injury to anterior structures such as the vena cava, aorta, and iliac vessels. Yeung ${ }^{86}$ recommended injecting discs with indocyanine green to act as a chromophore, thus maximizing delivery and minimizing the chance of injury to adjacent structures. The holmiumYAG system involves a unique pulsed laser that enables the adjustment of pulse width and frequency to cause disc cavitation and reduce intradisc pressure while minimizing injury to adjacent structures.

Overall, the combined results of several series demonstrated a 70 to $80 \%$ rate of long-lasting pain relief..$^{2,9}$ The 
only reported complication was one case of discitis in a series of 333 procedures, which was described by Choy, et al. ${ }^{8}$ Other possible complications of laser-assisted discectomy can include perforation of the aorta, vena cava, iliac vessels, or abdominal organs, and cauda equina syndrome. To date, however, there are no reported prospective controlled studies involving percutaneous laser discectomy. As such, the results of percutaneous laser discectomy for back and leg pain due to disc protrusions are still inconclusive. The largest experience in the literature, reported by Choy, et al., ${ }^{8}$ documented a $78.4 \%$ success rate with a 26 -month period follow up. Yeung ${ }^{86}$ reported an $84 \%$ rate of good or excellent results with the KTP/532 device. On the other hand, Sherk and associates ${ }^{73}$ observed no differences between treated and control groups in an analysis of responses to pain questionnaires or the presence of physical signs.

Yeung and colleagues ${ }^{87}$ published a recent retrospective review of 307 consecutive patients with lumbar disc herniation who were treated by posterolateral endoscopic laser discectomy. These authors showed satisfactory results in $89.3 \%$ of patients. The rate of response to the questionnaire was $91 \%$. The responses indicated that $90.7 \%$ of the respondents were satisfied with their surgical outcomes and would undergo the same endoscopic procedure again if faced with a similar herniation in the future. Poor outcomes occurred in $10.7 \%$ of the primary group and in $9.7 \%$ of the group responding to the questionnaire. The combined major and minor complication rate was $3.5 \%$.

\section{Arthroscopic Microdiscectomy}

Kambin and Hijikata and their colleagues independently developed mechanical tools for percutaneous nucleotomy. ${ }^{71}$ Refinements of the method involved the use of an automated system. ${ }^{45,57,58}$ The instruments were designed to remove disc material from the center of the disc and to decrease the amount of nucleus pulposus posterolaterally. Subsequent developments led to the design of a $2.7-\mathrm{mm}$ glass arthroscope combined with a videodiscoscope with a single working portal. ${ }^{32-34}$ The introduction of arthroscopic illumination and magnification allowed identification of the triangular working zone. The triangular working zone has been identified as a safe zone in the posterolateral anulus, which allows safe passage of instruments with minimal risk to the exiting nerve. ${ }^{32-36}$ Placement of the needle is confirmed with the aid of an intraoperative fluoroscope. Within the triangle, there is generally room for introduction of the coaxial instruments. The initial open procedure in which a tube is introduced posterolaterally was slowly replaced by a completely percutaneous operation in which a modified discoscope, working portals, and special instruments are used..$^{71}$

The mechanism of pain relief after arthroscopic microdiscectomy and central nucleotomy is controversial, but the theory involves the reduction in intradisc pressure, removal of inflammatory agents, and reduction of tension on the nerve root. Additionally, the arthroscopic approach provides the opportunity to inspect the anulus, spinal nerve, and foramina. All intraanular, subligamentous, and extraligamentous herniations are accessible via the arthroscopic microdiscectomy procedure. Nevertheless, se- questrated and migrated disc fragments cannot be safely removed using the arthroscopic microdiscectomy method.

Kambin $^{32,33}$ reported an $87 \%$ successful outcome rate with arthroscopic microdiscectomy. Others reported similar successes withthis procedure. ${ }^{27,70}$ Mayer and Brock, ${ }^{48}$ in a paper on a prospective randomized control trial, achieved favorable outcomes with minimal complications. The reported complications in the literature included discitis, instrument breakage, and psoas hematomas; no neurovascular complications arising from posterolateral access to the intervertebral discs of the lumbar spine have been encountered. Proper patient selection makes arthroscopic microdiscectomy an attractive option as a sameday surgical procedure. Negligible blood loss, avoidance of general anesthesia, and minimization of scar tissue can all contribute to desirable outcomes.

\section{Lumbar MED}

Because of familiarity, better long-term outcome studies, and the ability to address concomitant pathological bone and ligament conditions, microsurgical discectomy has been recognized as the surgery of choice for treating lumbar disc herniations by many surgeons when compared with other percutaneous procedures. In an attempt to achieve the same desirable outcomes as those provided by the microsurgical discectomy technique, by using a minimally invasive muscle splitting approach, a tubular retractor system for microdiscectomy was first developed in 1994. The system consists of a series of concentric dilators and thin-walled tubular retractors of variable length; its basic concept is the foundation on which several contemporary approaches to minimally invasive spinal fusion are based. The spine is accessed via serial dilation of the cleavage plane between the muscle fascicles. The midline supporting the musculoligamentous structures are left intact using this technique. In 1997, the MED system was introduced (Fig. 2). Since then, the MED procedure has become the most popular and successful of the minimally invasive procedures. The steep learning curve associated with the use of the endoscope for MED procedures initially deterred many surgeons from widespread accep-

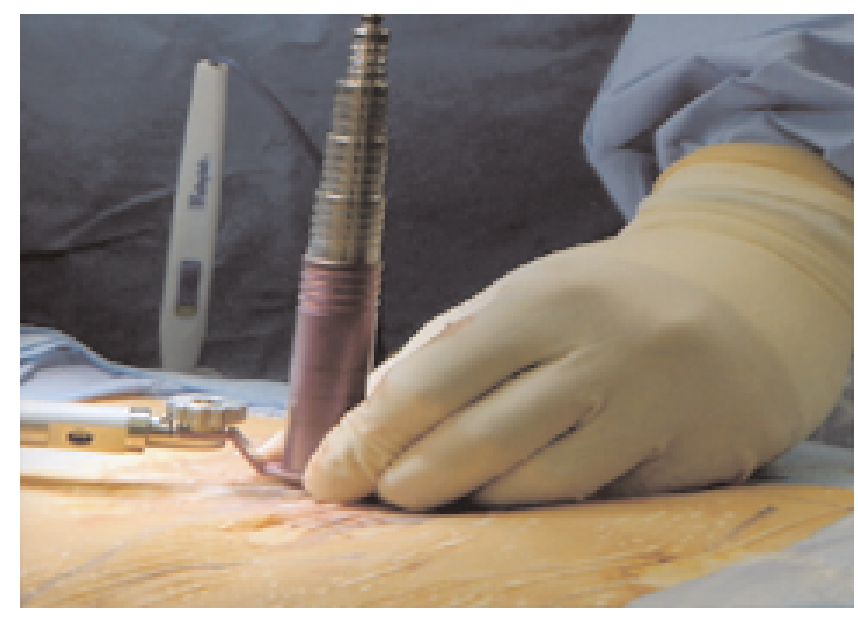

Fig. 2. Intraoperative photograph demonstrating the use of the MED system with sequential tubular dilators. 
tance of the technique. The lack of depth perception and stereoscopic visualization associated with the use of the endoscope compounded the steep learning curve of the procedure. The next generation of the MED system, called the METRx (Medtronic Sofamor Danek, Minneapolis, $\mathrm{MN}$ ), provided increased working space and better illumination. Surgery can now be performed using the operating microscope, loupes, an endoscope, or a combination of techniques, depending on the preference of the surgeon. Essentially, one can follow the same method as the open microdiscectomy. Currently, over 6000 MED procedures have been performed at more than 500 institutions. Using this procedure, surgeons can now also treat free-fragment disc herniations as well as canal stenosis, conditions that were previously unaddressed by other percutaneous procedures. At several centers this procedure is performed as a routine outpatient procedure without general anesthesia.

Although there have not been randomized prospective studies between microdiscectomy and MED, authors of many series have found comparable outcomes between the two methods. Muramatsu, et al., ${ }^{51}$ reported a series of 70 patients who underwent the MED procedure. Overall, earlier postoperative ambulation, reduced intraoperative blood loss, and decreased postoperative consumption of analgesic medications were noted in patients who underwent the MED procedure.

With the increasing popularity of the MED and METRx systems, further applications have been described. An MED technique for minimally invasive lumbar laminectomy and foraminotomy has been performed. Guiot and colleagues ${ }^{24}$ described the technical feasibility of decompression of lumbar stenosis via the MED system. Palmer, et al. ${ }^{60}$ used a unilateral approach with the METRx system to achieve bilateral decompression in 17 consecutive patients with spinal stenosis. The procedure was performed on an outpatient basis after induction of general anesthesia. Preoperative stenosis was severe at 13 levels, moderate to severe at eight, and moderate at one level. Postoperatively stenosis was absent at 13 levels, mild at seven, mild to moderate at one, and moderate at one level.

Overall, indications for the use of the MED system are similar to conventional open procedures. Its applications have also been successfully performed in obese patients and in patients who have undergone previous spinal operations. As an expanding use of the tubular retractor approach, further developments have been made in the area of minimally invasive lumbar fusion.

\section{LUMBAR FUSION}

\section{Laparoscopic Anterior LIF}

Prior to the 1980s, laparoscopic procedures were mainly used in the fields of gynecology and urology. The transition into general surgery began in the 1980 s when the first laparoscopic appendectomy was performed in Germany. In 1987, the first human laparoscopic cholecystectomy was performed in France. ${ }^{15}$ The widespread acceptance of this minimally invasive approach can best be appreciated by noting that within only 3 years after its introduction, more than $90 \%$ of all cholecystectomies were being performed laparoscopically. The significant advantages of transperitoneal laparoscopic surgical treatment include marked reductions in postoperative pain, early hospital discharges, and reduced incidences of postoperative ileus.

Anterior lumbar fusion was initially described by Burns $^{4}$ in 1933 for the treatment of spondylolisthesis. In 1991, Obenchain first described the laparoscopic approach to the lumbar spine for discectomy. ${ }^{71}$ In 1995, Mathews, et al., ${ }^{47}$ and Zucherman, et al. ${ }^{89}$ described the technique in detail and published preliminary outcome data for laparoscopic anterior lumbar fusion (Fig. 3). In 1999, Regan and associates ${ }^{63}$ published a prospective study in which open and laparoscopic methods of anterior lumbar fusion were compared. They demonstrated that patients who underwent the laparoscopic procedure had a shorter hospital stay and reduced blood loss, but an increased operative time. Operative time shortened in patients who underwent the laparoscopic procedure as surgeons' experiences increased. Operative complications were comparable in both groups, with an occurrence of $4.2 \%$ in those in whom the open approach was used and $4.9 \%$ in those in whom the laparoscopic approach was used. Overall, the device-related rate of repeated surgery was higher in the laparoscopy group $(4.7 \%$ compared with $2.3 \%)$, primarily as a result of intraoperative disc herniation. Conversion to an open procedure in patients who initially were treated laparoscopically was $10 \%$.

Authors of a more recent study did not favor the video-assisted laparoscopic approach. Escobar, et al., ${ }^{16}$ published a comparative analysis focusing on the complications of four techniques - a transperitoneal video assisted procedure with insufflation; a retroperitoneal endoscopic video-assisted procedure; minilaparotomy retroperitoneal surgery; and a traditional oblique muscle-splitting retroperitoneal surgery-for anterior LIF in 135 patients. The study revealed that the highest incidence of complications occurred in video-assisted laparoscopic approaches. Complications are primarily related to surgical exposure of the anterior spine, which can include damage to important vascular structures, the sympathetic plexus, or the abdominal viscera.

\section{Retroperitoneal Lumbar Fusion}

The retroperitoneal approach to the lumbar spine was first described by Iwahara in 1963 and is now being increasingly used for treatment of spondylolisthesis, ${ }^{38,69,76}$ degenerative disc disease, ${ }^{76}$ internal disc derangement, ${ }^{4,5}$ and instability, ${ }^{26}$ as well as for repeated operations. ${ }^{75,77}$ Endoscopic approaches to the retroperitoneal space, known as "retroperitoneoscopies" were initially described by urological surgeons in the 1990s. Gaur ${ }^{22}$ and McDougall and coworkers ${ }^{50}$ first used balloon dissection of the retroperitoneal space to enable laparoscopic visualization of the surrounding anatomy. This eventually gave rise to applications for treatment of lumbar disease. The balloon-assisted endoscopic retroperitoneal gasless procedure is a minimally invasive retroperitoneal approach to the anterior lumbar spine. A gasless retroperitoneal approach has additionally advantages. This procedure is similar to an open spinal procedure and conventional instruments may be implemented. Trocars with valves are not required and complications associated with carbon dioxide insufflation are avoided. Advances in interbody cage technology and artificial discs have generated a great deal of interest in an- 

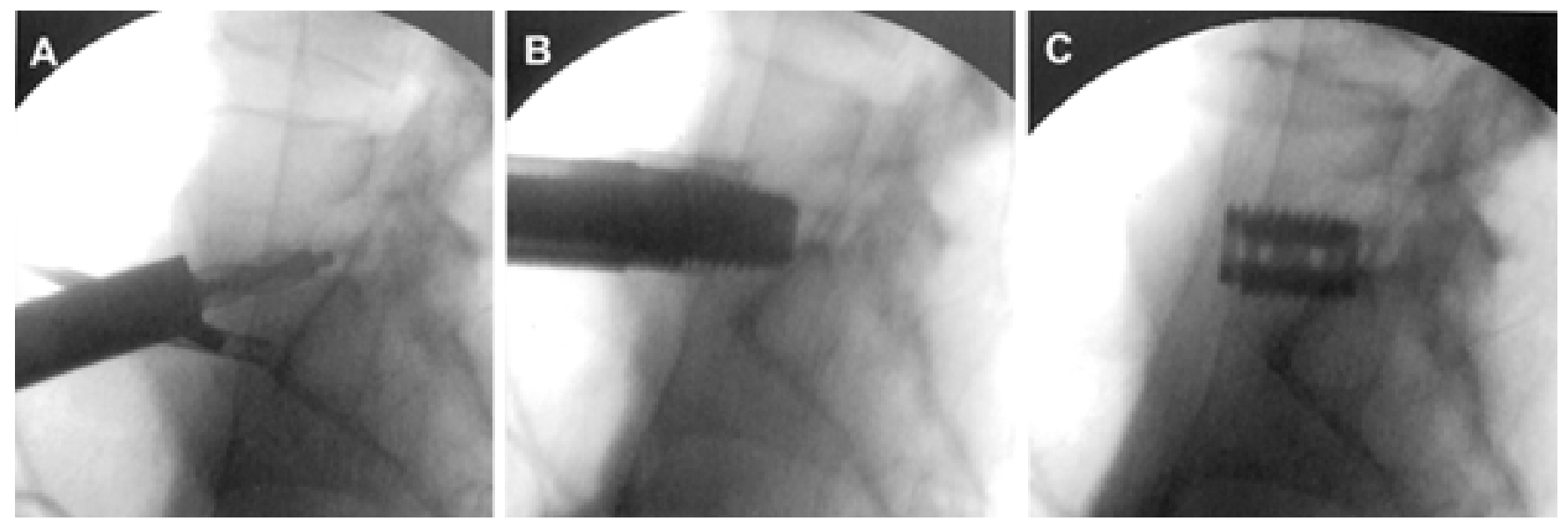

Fig. 3. Intraoperative fluoroscopic views showing the preparation of the L5-S1 disc space for an anterior LIF (A), placement of a cage in the prepared disc space (B), and the final placement of the cage for the L5-S1 anterior LIF (C), which was performed via a laparoscopic approach.

terior lumbar fusion. Minimal access techniques of treating the anterior lumbar spine will be important in optimizing clinical outcomes, in addition to preserving posterior load-bearing elements.

\section{Minimally Invasive Posterior and Transforaminal LIFs}

The concept of LIF, as initially described by Cloward in 1951, offers several advantages over traditional posterolateral arthrodesis, including a rich blood supply from the cancellous fusion bed, a load-bearing force occurring through the fusion bed, the ability to distract the disc space and neuroforamina, and the ability to restore segmental lordosis. Traditional open posterior LIF procedures have been reported to yield successful outcomes in approximately $80 \%$ of patients with fusion rates near $90 \%$. Since 2000, minimally invasive posterior LIF procedures have been performed to reduce iatrogenic injury, which can be incurred during the exposure process of the open procedure (Fig. 4). Long-term follow-up data are lacking, but retrospective reviews of minimally invasive posterior LIF performed with the aid of the microscope, premachined bone graft or cages, a virtual fluoroscope, and a percutaneous pedicle screw system were reported to yield clinical improvement more than 1 year postoperatively, which is comparable to the outcomes of an open procedure. ${ }^{17,18}$

Transforaminal LIF, a unilateral posterior approach for achieving an interbody arthrodesis, has gained recent popularity. The disc interspace is accessed by performing a unilateral facetectomy. Retraction of the nerve root is kept to a minimum, allowing for safer placement of the interbody graft. The METRx system can be used for exposure of the disc space and completion of the facetectomy. Placement of a premachined bone graft or cage supplemented with BMP can obviate the need for local harvesting of an autograft. Supplemental percutaneous pedicle fixation is added for completion of the transforaminal LIF procedure.

The unilateral transforaminal LIF approach for interbody fusion offers several advantages over the posterior LIF procedure. Retraction of the nerve root and dura mater is minimized, because of the lateral entry point, and this reduces the risk of neural injury. This lateral entrance into the disc space also makes revision surgeries less difficult, because there is less need to mobilize nerve roots that may be surrounded by epidural scar tissue. A potential disadvantage of unilateral transforaminal LIF is that direct nerve root decompression can only be performed unilaterally. With the increasing use of the tubular retractor system, however, bilateral foraminal decompression can be achieved via a unilateral approach, as previously described.

\section{THORACIC SPINE}

\section{Video-Assisted Thoracoscopic Surgery}

The history of thoracoscopy dates back to 1910 , when Jacobaeus performed the first thoracoscopic and laparo-

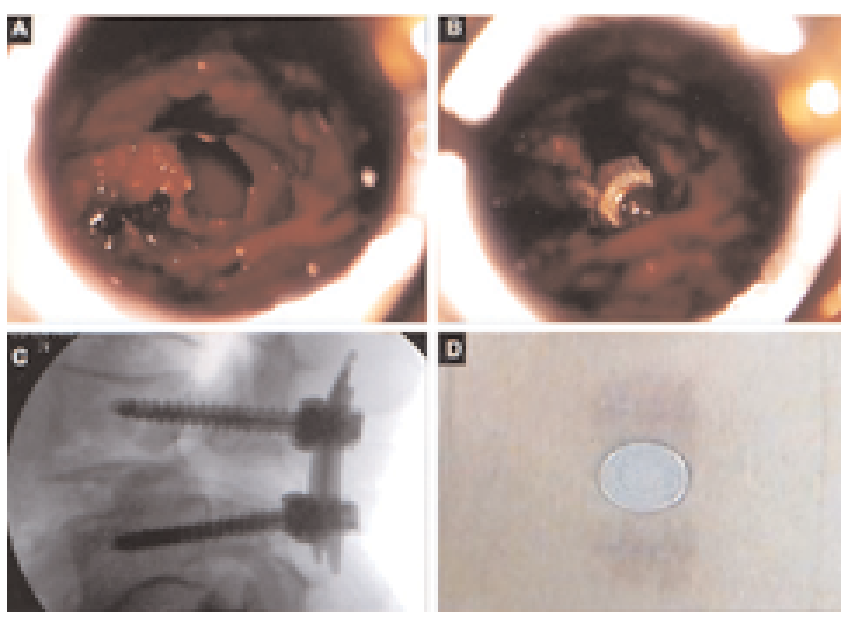

Fig. 4. Views obtained during and after a minimally invasive posterior LIF. A: A generous facetectomy and discectomy is performed through a tubular retractor system. B: An interbody graft is placed through a tubular retractor. C: Lateral lumbar x-ray film obtained after the procedure. D: Surgical wound shown after closure. 
scopic procedure. ${ }^{71}$ In 1990, the introduction of video imaging to standard endoscopy marked the modern era of thoracoscopic surgery. A description of video-assisted thoracic surgery was first reported in 1993 by Mack, et al. ${ }^{41}$ Video-assisted thoracic surgery has since played a major role in the treatment of thoracic disc herniations and spinal deformities requiring anterior release, as well as in corpectomies for the treatment of vertebral body tumors. ${ }^{49,56,62}$ Several published reports have demonstrated the efficacy of video-assisted thoracoscopic surgery for the excision of thoracic disc herniations. ${ }^{29,65}$ Thoracoscopic spine surgery has also made treatment of hyperhidrosis possible in a minimally invasive way. Picetti, et al., ${ }^{61}$ performed corrective surgery with the aid of a thoracoscope in 50 patients with thoracic scoliosis. Endoscopic instrumentation was successfully performed in all patients. Curve corrections averaged $50.2 \%$, and this rate improved to $68.6 \%$ in the last 10 cases. The preoperative axial rotation (as measured using a scoliometer) averaged $16^{\circ}$; this was corrected to $5^{\circ}$. Postoperative pain was reduced as was the duration of postoperative analgesic use in patients treated thorascopically, compared with patients treated with formal open procedures.

In the trauma series reported by Khoo and associates $^{37} 371$ patients with fractures of the thoracic and thoracolumbar spine (T3-L3) were treated with a thoracoscope-assisted procedure (Fig. 5). Seventy-three percent of the fractures were located at the thoracolumbar junction. In $49 \%$ of the patients, mobilization of the diaphragm was performed thorascopically to expose the fracture site. The severe complication rate was low $(1.3 \%)$, with one case each of aortic injury, splenic contusion, neurological deterioration, cerebrospinal fluid leak, and severe wound infection. Compared with a group of 30 patients who were treated with open thoracotomy, patients treated thoracoscopically required $42 \%$ less narcotic agents for pain treatment after the operation.

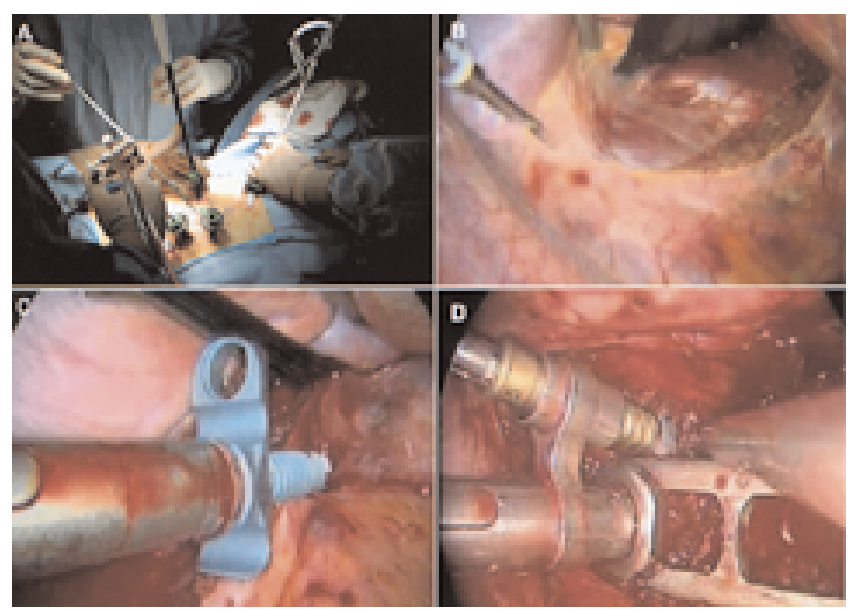

Fig. 5. Intraoperative photographs obtained during thoracoscopic surgery for a thoracolumbar fixation. A: External view of thorascopic surgery. B: Thoracoscopic view inside the pleural cavity. A special fan retractor is used to retract the diaphragm. Minimal dissection of the diaphragm was performed to expose the thoracolumbar junction. C: Thoracoscope-assisted screw fixation. D: Final construct after thoracoscope-assisted thoracolumbar fixation.
A thoracoscopic approach can only access the anterior and anterolateral aspects of the vertebrae and spinal canal. It cannot adequately expose the posterior elements, the contralateral pedicle, or the transverse process. Thoracoscopic surgery, like endoscopic surgery, will require a steep learning curve, but it has the advantages of reducing postthoracotomy pain syndromes and exposure-related morbidity.

\section{CERVICAL SPINE}

\section{Cervical Microendoscopic Discectomy}

In selected patients with laterally herniated disc fragments, isolated foraminal narrowing, multilevel foraminal narrowing without central stenosis, or continued nerve root symptoms after anterior cervical discectomy and fusion, a posterior cervical approach will be necessary. Although the anterior approach to the cervical spine has become increasingly popular, the posterior cervical discectomy technique, as described by Scoville and associates $^{72}$ is quite effective in relieving radicular pain and avoids the need for a fusion. The disadvantage of the standard posterior approach, however, is significant paraspinous muscle dissection, postoperative axial neck pain, potential instability, and subsequent deformity.

By applying the MED system to the lumbar area, the disadvantages of the posterior cervical exposure process can be minimized by avoiding the need for a midline muscle dissection. Dilators are sequentially inserted through the posterior neck musculature and docked at the junction of the lamina and the lateral mass. An intraoperative fluoroscope is used to confirm the level and correct placement of the tube (Fig. 6). The microsurgical procedure is performed through the tubular retractor, as it is during an open procedure.

Roh, et al. ${ }^{64}$ performed posterior cervical foraminotomies by using either the MED system or conventional open techniques in four cadaveric specimens. They were able to demonstrate greater decompression by using the MED procedure and showed the possibility of minimally invasive cervical foraminal decompression and discectomy. Adamson ${ }^{1}$ stated that excellent or good results were obtained in $97 \%$ of his patients treated by cervical MED

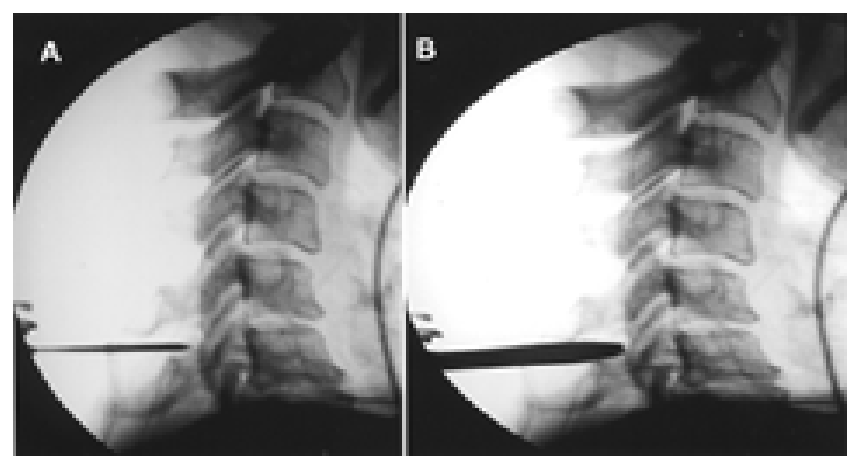

Fig. 6. Intraoperative fluoroscopic views obtained during a cervical MED procedure. The patient is in the sitting position. A: Initial K-wire placement. B: Placement of the dilator over the K-wire at the operative level. 
for unilateral cervical radicular syndromes due to foraminal stenosis or disc herniations. No serious complications were reported.

\section{Minimally Invasive Cervical Laminoplasty}

Expansile laminoplasty has been successfully used to treat cervical myelopathy that is attributable to canal stenosis; however, detachment of the posterior cervical muscles is thought to contribute to postoperative axial neck pain and kyphosis. Minimizing the amount of muscular dissection might reduce the likelihood of these sequelae. Wang and associate ${ }^{80}$ assessed the feasibility of a minimally invasive laminoplasty technique by applying it to cadaveric spines. A 22-mm tubular dilator port was used to access lamina-facet junctions from C-2 to C-7 through bilateral stab incisions made at C4-5 and C5-6. Troughs at the lamina-facet junctions were drilled bilaterally and the contiguous laminae were lifted en bloc from one side. Ten-millimeter rib allograft spacers were inserted to maintain a gap on the open side. These researchers found that exposure of six cervical levels can be accomplished by creating two small incisions on each side. The diameter of the midsagittal spinal canal was increased by a mean of $38 \%$ and the area of the spinal canal was increased by an average of $43 \%$ at the level of C-5.

\section{Minimally Invasive Cervical Lateral Mass Screw Fixation}

Although not without its limitations, cervical instrumentation can also be accomplished via a minimally invasive approach. A "novel" surgical technique of lateral mass screw fixation through a special tunnel retractor has recently been described..$^{81}$ The procedure is performed while the patient is in the prone position by using tubular retractors, which are introduced two or three levels below the pathological region, at an angle used for placement of the lateral mass screws. Dorsal elevation of the retractor system will provide room for placement of the rod. This technique can be applied to three contiguous cervical levels.

\section{VERTEBROPLASTY AND KYPHOPLASTY}

Developed in France in the late 1980s, minimally invasive vertebroplasty involves the percutaneous injection of PMMA into a fractured vertebral body. ${ }^{14}$ Although this does not reexpand a collapsed vertebra, it reinforces and stabilizes the fracture, which seems to alleviate pain. The procedure was first used to treat aggressive vertebral hemangiomas ${ }^{14}$ and was later applied to other lesions that weaken the vertebral body, including osteolytic metas-

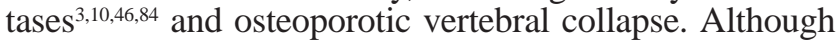
the European experience with vertebroplasty in the setting of spinal metastases and myeloma is more extensive, indications for treatment in North America are currently heavily weighted toward osteoporotic bone disease. Percutaneous balloon kyphoplasty is a recent modification of the vertebroplasty method and involves inflation of a balloon within a collapsed vertebral body, to restore height and reduce kyphotic deformity, followed by stabilization with PMMA. The risk of cement extravasation is theoretically reduced because the balloon creates a void within the ver- tebral body into which cement can be injected under relatively low pressure. Nevertheless, vertebroplasty still has been known to be successful for the treatment of compression fracture of the spine (Fig. 7).

In addition to PMMA and bone mineral cement, several alternative biological materials have been used in attempts to augment compromised vertebral bodies. The efficacy of osteoinductive growth factors (transforming growth factor- $\beta$, BMP-2, and BMP-7) in enhancing arthrodesis is currently being studied in patients undergoing spinal instrumentation.

\section{INTRADISCAL ELECTROTHERMAL THERAPY}

Saal and Saal ${ }^{66}$ hypothesized that thermal energy might play a role in the treatment of internal disc disruption and thus chronic low-back pain. Intradisc electrothermal coagulation is a therapeutic innovation specifically designed to treat discogenic pain. The most commonly used electrosurgery unit, the Ellman Surgitron IEC, produces ultrahigh-frequency radio-wave energy, which is delivered through modified monopolar and bipolar tools. The energy is filtered back to the electrosurgery unit without causing adjacent tissue damage. ${ }^{71}$ In the normal intervertebral disc, sensory nerves do not penetrate beyond the outer one third of the anulus fibrosis; in degenerative disc disease, however, neoneuralization can occur, resulting in new nerve fibers that contribute to a painful sensation. The diagnosis of this condition is based largely on the patient's medical history and on radiological findings. Discograms, although controversial, are often used as additional confirmatory tests.

Intradiscal electrothermal therapy delivers targeted thermal energy designed to shrink collagen fibrils, cauterize granulation tissue, and coagulate nerve tissue in the posterior anulus fibrosus. Intradiscal electrothermal coagulation requires percutaneously threading a flexible heating electrode into the disc, such that the electrode passes circumferentially around the inner surface of the disc. Direct application of thermal energy to the intervertebral disc is thought to reduce discogenic pain either by thermal coag-
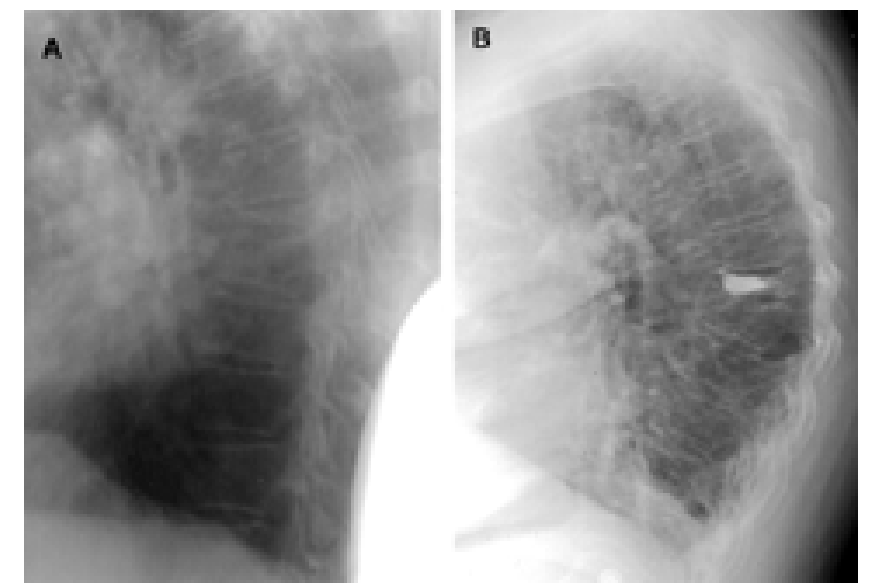

Fig. 7. Lateral radiographs. A: Preoperative image demonstrating a severe osteoporotic compression fracture at T-7. B: Image obtained after vertebroplasty. 
ulation of nociceptors or by increasing the stability of the disc via contraction of collagen Type I fibers.

Saal and Saal ${ }^{66,68}$ recently developed a novel resistive heating catheter that can be introduced into the anulus and navigated through the nucleus and around the inner wall of the anulus. Personnel at Oratec Interventions, Inc., compared 36 patients treated with IDET with those treated conservatively for chronic discogenic back pain. To be eligible for the study, patients were required to satisfy criteria for internal disc disruption, as characterized by the International Association for the Study of Pain, that is, pathological findings on a discogram and evidence of a Grade III anular tear on a CT scan. The results of that study indicated that $60 \%$ of the selected patients experienced profound reductions in pain. ${ }^{66,68}$

Saal and $\mathrm{Saal}^{67}$ showed that the IDET-treated study group (58 patients) reported a statistically significant improvement in visual analog pain scores and in bodily pain on the SF-36 Health Survey scores after 2 years of followup review. The IDET-treated group demonstrated improvement in physical function, as noted by statistically significant improvements in the amount of time the sitting position was tolerable and in the physical function SF-36 scores. Additionally, there were improvements in all SF36 subscales concerning quality of life.

The use of high-frequency radio waves has proved to be efficacious in minimally invasive spine surgery. The studies have evoked some optimism for the use of IDET in the treatment of discogenic pain in properly selected patients; this may help avoid or delay a spinal fusion in some patients.

\section{IMAGE-GUIDED SURGERY}

Since its introduction, transpedicular screw fixation has been extensively used in various spinal disorders to promote fusion and stabilization. Screw misplacement can lead to undesirable neurovascular complications. Pedicle screw placement in patients with deformities carries an even greater risk of serious complications. Weinstein and coworkers $^{85}$ reported perforation of the cortex due to pedicle screws in close to $20 \%$ of these cases. To increase the accuracy of screw placement, various methods have been used to target the pedicle more effectively with respect to the trajectory and the depth of screw placement.

Image-guided systems are widely used in intracranial surgery and have been adapted to assist with screw placement since the mid-1990s. ${ }^{23,52}$ The use of image-guided systems for pedicle screw placement has improved the accuracy of the placement. The system relies on precise localization of the pedicles by using CT scanning. Furthermore, by replacing direct visualization with radiographic visualization, it has enabled a reduction in sugical exposure, duration, and blood loss. Foley, et al., ${ }^{17}$ described "virtual fluoroscopy" and its successful use in various spinal procedures including pedicle screw insertion, interbody cage placement, odontoid screw insertion, and atlantoaxial transarticular screw fixation.

Nolte and associates ${ }^{52}$ described the principles of computer-assisted pedicle screw fixation. An infrared camera (Optotrak; Northern Digital, Waterloo, ON, Canada) was used to track specific instruments (pedicle probe, awl, and space pointer) that were equipped with light-emitting di- odes. The dynamic reference was fixed to the spinous process of the vertebra to receive instrumentation. Normal bone landmarks and their correlations with images confirmed the calibration accuracy. Using that computerized system, Nolte, et al., ${ }^{52}$ reported a pedicle screw misplacement rate of $4.3 \%$ under clinical conditions. In contrast, Choi, et al., ${ }^{7}$ reported the use of computer-assisted fluoroscopic targeting for pedicle screw fixation. The authors compared the accuracy of pedicle screw placement accompanied by the fluoroscopy-guided system with the image-guided system and observed no significant differences.

The recent development of isocentric C-arm fluoroscopy, in which CT images are generated with the aid of an intraoperative fluoroscope, may offer another means of three-dimensional navigation by using a two-dimensional intraoperative imaging source (Fig. 8). With increasing familiarity, image-guided surgery will be a very useful adjunct to the further development of minimally invasive surgery.

\section{CONCLUSIONS}

The history of minimalism in spinal surgery has moved forward in great leaps. Rapid technological advancements of the last two decades have made minimal access surgery possible. Virtually, all aspects of the spinal axis can be approached and treated in a minimally invasive approach. Core to the concept of minimally invasive surgery is the reduction of iatrogenically induced injury while achieving the goals of the surgery. With the innovation of better optics and video equipment, retractor and instrumentation systems, image guidance systems, and new biological agents, the majority of traditional "open" spinal procedures can now be performed in a minimalistic way. For most minimally invasive surgical procedures, however, long-term prospective controlled data are still lacking. In addition, the use of new technology will require a new learning curve that may be discomforting for many surgeons. Special skills may be needed that are beyond those of traditional open surgery. With the resource of the Inter-

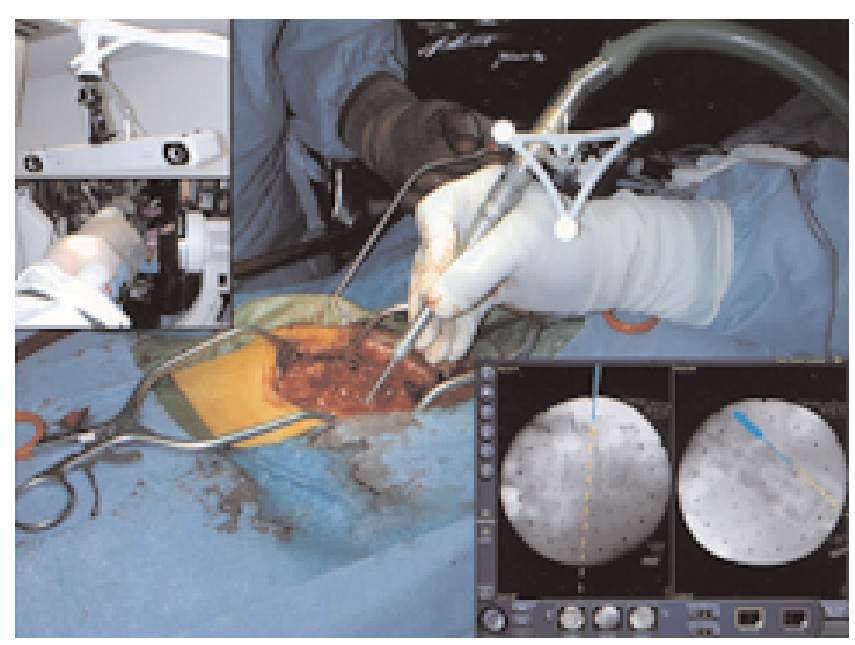

Fig. 8. Intraoperative images demonstrating the use of "virtual fluoroscopy" for pedicle screw placement. 
net, patients are becoming increasingly informed or perhaps misinformed. It will be advantageous for practicing surgeons to be knowledgeable of available minimally invasive procedures and their outcomes in the course of their patient consultation. The goals of minimally invasive surgery are quite laudable; as such, patients will demand it.

\section{References}

1. Adamson TE: Microendoscopic posterior cervical laminoforaminotomy for unilateral radiculopathy: results of a new technique in 100 cases. J Neurosurg (Spine 1) 95:51-57, 2001

2. Ascher PW, Heppner F: CO2-laser in neurosurgery. Neurosurg Rev 7:123-133, 1984

3. Barr JD, Barr MS, Lemley TJ, et al: Percutaneous vertebroplasty for pain relief and spinal stabilization. Spine 25:923-928, 2000

4. Burns BH: An operation for spondylolisthesis. Lancet 1:1233, 1933

5. Calandruccio RA, Benton BF: Anterior lumbar fusion. Clin Orthop 35:63-68, 1964

6. Caspar W: A new surgical procedure for lumbar disc herniation causing less tissue damage through a microsurgical approach. Adv Neurosurg 4:74-80, 1977

7. Choi WW, Green BA, Levi AD: Computer-assisted fluoroscopic targeting system for pedicle screw insertion. Neurosurgery 47:872-878, 2000

8. Choy DS, Ascher PW, Saddekni S, et al: Percutaneous laser disc decompression. A new therapeutic modality. Spine 17: 949-956, 1992

9. Choy DS, Case RB, Fielding W, et al: Percutaneous laser nucleolysis of lumbar disks. N Engl J Med 317:771-772, 1987 (Letter)

10. Cotten A, Dewatre F, Cortet B, et al: Percutaneous vertebroplasty for osteolytic metastases and myeloma: effects of the percentage of lesion filling and the leakage of methyl methacrylate at clinical follow-up. Radiology 200:525-530, 1996

11. Dabezies EJ, Langford K, Morris J, et al: Safety and efficacy of chymopapain (Discase) in the treatment of sciatica due to a herniated nucleus pulposus. Results of a randomized, double-blind study. Spine 13:561-565, 1988

12. Davis GW, Onik G: Clinical experience with automated percutaneous lumbar discectomy. Clin Orthop 238:98-103, 1989

13. Davis GW, Onik G, Helms C: Automated percutaneous discectomy. Spine 16:359-363, 1991

14. Deramond H, Depriester C, Galibert P, et al: Percutaneous vertebroplasty with polymethylmethacrylate. Technique, indications, and results. Radiol Clin North Am 36:533-546, 1998

15. Dubois F, Icard P, Berthelot G, et al: Coelioscopic cholecystectomy: Preliminary report of 36 cases. Ann Surg 211:60-62, 1990

16. Escobar E, Transfeldt E, Garvey T, et al: Video-assisted versus open anterior lumbar spine fusion surgery: a comparison of four techniques and complications in 135 patients. Spine 28: 729-732, 2003

17. Foley KT, Gupta SK: Percutaneous pedicle screw fixation of the lumbar spine: preliminary clinical results. J Neurosurg (Spine 1) 97:7-12, 2002

18. Foley KT, Holly LT, Schwender JD: Minimally invasive lumbar fusion. Spine 28:S26-S35, 2003

19. Fraser RD: Chymopapain for the treatment of intervertebral disc herniation. A preliminary report of a double-blind study. Spine 7:608-612, 1982

20. Fries JW, Abodeely DA, Vijungco JG, et al: Computed tomography of herniated and extruded nucleus pulposus. J Comput Assist Tomogr 6:874-887, 1982

21. Garvin PJ, Jennings RB, Smith L, et al: Chymopapain: a pharmacologic and toxicologic evaluation in experimental animals. Clin Orthop 41:204-223, 1965
22. Gaur DD: Laparoscopic operative retroperitoneoscopy: use of a new device. J Urol 148:1137-1139, 1992

23. Glossop ND, Hu RW, Randle JA: Computer-aided pedicle screw placement using frameless stereotaxis. Spine 21: 2026-2034, 1996

24. Guiot BH, Khoo LT, Fessler RG: A minimally invasive technique for decompression of the lumbar spine. Spine 27: 432-438, 2002

25. Gunzburg R, Fraser RD, Moore R, et al: An experimental study comparing percutaneous discectomy with chemonucleolysis. Spine 18:218-226, 1993

26. Harmon PH: Anterior extraperitoneal lumbar disk excision and vertebral body fusion. Clin Orthop 18:169-198, 1960

27. Hermantin FU, Peters T, Quartararo L, et al: A prospective, randomized study comparing the results of open discectomy with those of video-assisted arthroscopic microdiscectomy. J Bone Joint Surg Am 81:958-965, 1999

28. Hijikata S: Percutaneous nucleotomy. A new concept technique and 12 years' experience. Clin Orthop 238:9-23, 1989

29. Horowitz MB, Moossy JJ, Julian T, et al: Thoracic discectomy using video assisted thoracoscopy. Spine 19:1082-1086, 1994

30. Jansen EF, Balls AK: Chymopapain: a new crystalline proteinase from papaya latex. J Biol Chem 137:459-460, 1941 (Letter)

31. Javid MJ, Nordby EJ, Ford LT, et al: Safety and efficacy of chymopapain (Chymodiactin) in herniated nucleus pulposus with sciatica. Results of a randomized, double-blind study. JAMA 249:2489-2494, 1983

32. Kambin P: Arthroscopic microdiscectomy of the lumbar spine. Clin Sports Med 12:143-150, 1993

33. Kambin P: Arthroscopic microdiskectomy. Mt Sinai J Med 58: 159-164, 1991

34. Kambin P, Cohen LF: Arthroscopic microdiscectomy versus nucleotomy techniques. Clin Sports Med 12:587-598, 1993

35. Kambin P, Gellman H: Percutaneous lateral discectomy of the lumbar spine: a preliminary report. Clin Orthop 174:127-132, 1983

36. Kambin P, Sampson S: Posterolateral percutaneous suctionexcision of herniated lumbar intervertebral discs. Report of interim results. Clin Orthop 207:37-43, 1986

37. Khoo LT, Beisse R, Potulski M: Thoracoscopic-assisted treatment of thoracic and lumbar fractures: a series of 371 consecutive cases. Neurosurgery 51 (Suppl 5):104-117, 2002

38. Kim SS, Denis F, Lonstein JE, et al: Factors affecting fusion rate in adult spondylolisthesis. Spine 15:979-984, 1990

39. Liebler WA: Percutaneous laser disc decompression: clinical experience with the Nd: YAG and KTP lasers, in Sherk HH (ed): Spine: Laser Discectomy. Philadelphia: Hanley \& Belfus, 1993, Vol 7, pp 55-65

40. Lorenz M, McCulloch J: Chemonucleolysis for herniated nucleus pulposus in adolescents. J Bone Joint Surg Am 67: 1402-1404, 1985

41. Mack MJ, Regan JJ, Bobechko WP, et al: Application of thoracoscopy for diseases of the spine. Ann Thorac Surg 56: 736-738, 1993

42. Malis JL: Technical contributions of Leonard I. Malis. Mt Sinai J Med 64:172-181, 1997

43. Mansfield F, Polivy K, Boyd R, et al: Long-term results of chymopapain injections. Clin Orthop 206:67-69, 1986

44. Maroon JC, Abla A: Microdiscectomy versus chemonucleolysis. Neurosurgery 16:644-649, 1985

45. Maroon JC, Onik G, Sternau L: Percutaneous automated discectomy. A new approach to lumbar surgery. Clin Orthop 238: 64-70, 1989

46. Martin JB, Jean B, Sugiu K, et al: Vertebroplasty: clinical experience and follow-up results. Bone 25 (Suppl 2):11S-15S, 1999

47. Mathews HH, Evans MT, Molligan HJ, et al: Laparoscopic discectomy with anterior lumbar interbody fusion: A preliminary review. Spine 20:1797-1802, 1995

48. Mayer HM, Brock M: Percutaneous endoscopic discectomy: 
surgical technique and preliminary results compared to microsurgical discectomy. J Neurosurg 78:216-225, 1993

49. McAfee PC, Regan JR, Zdeblick T, et al: The incidence of complications in endoscopic anterior thoracolumbar spinal reconstructive surgery. A prospective multicenter study comprising the first 100 consecutive cases. Spine 20:1624-1632, 1995

50. McDougall EM, Clayman RV, Fadden PT: Retroperitoneoscopy: the Washington University Medical School experience. Urology 43:446-452, 1994

51. Muramatsu K, Hachiya Y, Morita C: Postoperative magnetic resonance imaging of lumbar disc herniation: comparison of microendoscopic discectomy and Love's method. Spine 26: 1599-1605, 2001

52. Nolte LP, Zamorano LJ, Jiang Z, et al: Image-guided insertion of transpedicular screws. A laboratory set-up. Spine 20: 497-500, 1995

53. Nordby EJ, Brown MD: Present status of chymopapain and chemonucleolysis. Clin Orthop 129:79-83, 1977

54. Nordby EJ, Javid MJ: Continuing experience with chemonucleolysis. Mt Sinai J Med 67:311-313, 2000

55. Nordby EJ, Lucas GL: A comparative analysis of lumbar disk disease treated by laminectomy or chemonucleolysis. Clin Orthop 90:119-129, 1973

56. Nymberg SM, Crawford AH: Video-assisted thoracoscopic releases of scoliotic anterior spines. AORN J 63:561-576, 1996

57. Onik G, Helms CA, Ginsburg L, et al: Percutaneous lumbar diskectomy using a new aspiration probe. AJR 144: 1137-1140, 1985

58. Onik G, Helms CA, Ginsberg L, et al: Percutaneous lumbar diskectomy using a new aspiration probe: porcine and cadaver model. Radiology 155:251-252, 1985

59. Onik G, Mooney V, Maroon JC, et al: Automated percutaneous discectomy: a prospective multi-institutional study. Neurosurgery 26:228-233, 1990

60. Palmer S, Turner R, Palmer R: Bilateral decompression of lumbar spinal stenosis involving a unilateral approach with microscope and tubular retractor system. J Neurosurg (Spine 2) 97: 213-217, 2002

61. Picetti GD III, Pang D, Bueff HU: Thoracoscopic techniques for the treatment of scoliosis: early results in procedure development. Neurosurgery 51:978-984, 2002

62. Regan JJ, Mack MJ, Picetti GD III: A technical report of videoassisted thoracoscopy in thoracic spinal surgery. Preliminary description. Spine 20:831-837, 1995

63. Regan JJ, Yuan H, McAfee PC: Laparoscopic fusion of the lumbar spine: minimally invasive spine surgery. A prospective multicenter study evaluating open and laparoscopic lumbar fusion. Spine 24:402-411, 1999

64. Roh SW, Kim DH, Cardoso AC, et al: Endoscopic foraminotomy using MED system in cadaveric specimens. Spine 25: 260-264, 2000

65. Rosenthal D, Rosenthal R, de Simone A: Removal of a protruded thoracic disc using microsurgical endoscopy. A new technique. Spine 19:1087-1091, 1994

66. Saal JA, Saal JS: Intradiscal electrothermal treatment for chronic discogenic low back pain: a prospective outcome study with minimum 1-year follow-up. Spine 25:2622-2627, 2000

67. Saal JA, Saal JS: Intradiscal electrothermal treatment for chronic discogenic low back pain: prospective outcome study with a minimum 2-year follow-up. Spine 27:966-974, 2002

68. Saal JS, Saal JA: Management of chronic discogenic low back pain with a thermal intradiscal catheter. A preliminary report. Spine 25:382-388, 2000

69. Sacks S: Anterior interbody fusion of the lumbar spine. Indications and results in 200 cases. Clin Orthop 44:163-170, 1966

70. Savitz MH: Same-day microsurgical arthroscopic lateral-approach laser-assisted (SMALL) fluoroscopic discectomy. J Neurosurg 80:1039-1045, 1994
71. Savitz MH, Chiu JC, Yeung AT (eds): The Practice of Minimally Invasive Spinal Technique. Richmond, VA: AAMISMS Education Press, 2000

72. Scoville WB, Dohrmann GJ, Corkill G: Late results of cervical disc surgery. J Neurosurg 45:203-210, 1976

73. Sherk HH, Black JD, Prodoehl JA, et al: Laser diskectomy. Orthopedics 16:573-576, 1993

74. Smith L: Enzyme dissolution of the nucleus pulposus in humans. JAMA 187:137-140, 1964

75. Sorensen KH: Anterior interbody lumbar spine fusion for incapacitating disc degeneration and spondylolisthesis. Acta Orthop Scand 49:269-277, 1978

76. Stauffer RN, Coventry MB: Anterior interbody lumbar spine fusion. Analysis of Mayo Clinic series. J Bone Joint Surg Am 54:756-768, 1972

77. Takahashi K, Kitahara H, Yamagata M: Long-term results of anterior interbody fusion for treatment of degenerative spondylolisthesis. Spine 15:1211-1215, 1990

78. Tregonning GD, Transfeldt EE, McCulloch JA, et al: Chymopapain versus conventional surgery for lumbar disc herniation. 10-year results of treatment. J Bone Joint Surg Br 73: 481-486, 1991

79. Troussier B, Lebas JF, Chirossel JP, et al: Percutaneous intradiscal radio-frequency thermocoagulation. A cadaveric study. Spine 20:1713-1718, 1995

80. Wang MY, Green BA, Coscarella E, et al: Minimally invasive cervical expansile laminoplasty: an initial cadaveric study. Neurosurgery 52:370-373, 2003

81. Wang MY, Prusmack CJ, Green BA, et al: Minimally invasive lateral mass screw in the treatment of cervical facet dislocations: technical note. Neurosurgery 52:444-448, 2003

82. Watts C: Use of chymopapain in children. J Neurosurg 59: 1108,1983

83. Watts C, Hutchison G, Stern J, et al: Comparison of intervertebral disc disease treatment by chymopapain injection and open surgery. J Neurosurg 42:397-400, 1975

84. Weill A, Chiras J, Simon JM, et al: Spinal metastases: indications for and results of percutaneous injection of acrylic surgical cement. Radiology 199:241-247, 1996

85. Weinstein JN, Spratt KF, Spengler D, et al: Spinal pedicle fixation: Reliability and validity of roentgenogram-based assessment and surgical factors on successful screw placement. Spine 13:1012-1018, 1988

86. Yeung AT: Consideration for the use of the KTP laser for disc decompression and ablation, in Sherk HH (ed): Spine: Laser Discectomy. Philadelphia: Hanley \& Belfus, 1993, Vol 7, pp 67-93

87. Yeung AT, Tsou PM: Posterolateral endoscopic excision for lumbar disc herniation: surgical technique, outcome, and complications in 307 consecutive cases. Spine 27:722-731, 2002

88. Yonezawa T, Onomura T, Kosaka R, et al: The system and procedures of percutaneous intradiscal laser nucleotomy. Spine 15:1175-1185, 1990

89. Zucherman JF, Zdeblick TA, Bailey SA, et al: Instrumented laparoscopic spinal fusion. Preliminary results. Spine 20: 2029-2035, 1995

Manuscript received November 17, 2003.

Accepted in final form December 11, 2003.

Address reprint requests to: Daniel H. Kim, M.D., Department of Neurosurgery, Stanford University Medical Center, Room R-201, Edwards Building, 300 Pasteur Drive, Stanford, California 943055327. email: neurokim@stanford.edu. 